\title{
La experiencia de la teología: explorar lo teologal en la profundidad de lo humano y de la sociedad ${ }^{1}$
}

\author{
The theology experience: exploring theology from human and societal \\ depths
}

\author{
Marc Dumas \\ Doctor en Teología \\ Universidad de Sherbrooke \\ Marc.Dumas@USherbrooke.ca \\ Fecha de recepción: 23/04/2020 \\ Fecha de aceptación: 22/07/2020
}

Cómo citar este artículo: M. Dumas. (2020). "La experiencia de la teología: explorar lo teologal en la profundidad de lo humano y de la sociedad" en Palabra y Razón. Revista de Teología, Filosofía y Ciencias de la Religión. No 17 Julio 2020, pp 9-24 https://doi.org/10.29035/pyr.17.9

Resumen: En este artículo exploraremos los cruces interdisciplinares desde un punto de vista teológico, con el propósito de abrir espacios indeterminados, de vida o de negatividad, que permiten imaginar y construir un futuro posible. Desde este interés se desprenden cuestiones fascinantes que reúnen asuntos esenciales de ciertas prácticas teológicas contemporáneas. Evocaremos, en principio, las difíciles condiciones de la práctica teológica en la actualidad, al menos en aquellas regiones donde los procesos de secularización han producido un efecto de achatamiento. Personalmente, uso el término "teologal" para referirme a aquello que abre a la descoincidencia.

Palabras claves: Teologal / humano / descoincidencia / experiencia / interrupción

Abstract: This article explores the interdisplinary crossings from a theological point of view, with the purpose of opening inter-determinate spaces, of life or of negativity, which allow to imagine and to build a possible future. From this interest, fascinating questions emerge that meet certain essential contemporary theological practices. Evoking, in principle, the difficult conditions of theological practices today, at least in those regions where the secularization processes have produced a flattening effect. Personally, the use of the term "theological" refers what opens up to dis-coincidence.

Keywords: Theology / human / dis-coincidence / experience / interruption

1 Texto traducido al español por el Dr. Javier Agüero Águila, director Departamento de Filosofía, Universidad Católica del Maule. 
M. Dumas. (2020). "La experiencia de la teología: explorar lo teologal en la profundidad de lo humano y de la sociedad" en Palabra y Razón. Revista de Teología, Filosofía y Ciencias de la Religión. № 17 Julio 2020, pp 9-24 https://doi.org/10.29035/pyr.17.9

\section{Condiciones difíciles para la práctica teológica²}

La práctica teológica está hoy en día puesta en cuestión en todas partes. Casi siempre presente desde la fundación de las universidades. Nos preguntamos ahora por su presencia en las universidades subvencionadas por fondos públicos. Quien dice teología subentiende una confesión, una adhesión a un corpus dogmático. Esto contravendría a la misión universitaria, la que favorecería a unos creyentes y no a otros. ¿No se debería entonces acoger en las universidades, facultades ortodoxas, protestantes, incluso judías, musulmanas, entre otras? ¿No deberíamos migrar hacia una facultad de ciencias humanas de las religiones, neutra y libre de todas las posibles presiones confesionales? ${ }^{3}$

Diferentes instancias eclesiales desconfían de una teología menos orgánica y más crítica. Según ellas, los trabajos teológicos deben simplemente servir de apoyo orgánico, incluso ideológico a la institución, dejando de lado de esta manera aquella mirada crítica tan esperada por nuestros contemporáneos. Sin embargo, los trabajos teológicos ¿no deben acoger y criticar tanto las lecturas institucionales como las proposiciones mundanas? Inscritos en una tradición, sensibles a la cultura, las teólogas y teólogos colaboran con una mejor inteligencia de la fe para su comunidad y su sociedad, sabiendo que esto puede engendrar frecuentemente tensiones con la jerarquía.

Social y culturalmente, el declive de las instituciones religiosas por una parte y el retorno de lo religioso al margen por otra justifican el cuestionamiento de la teología. La teología es más bien tímida ante la emergencia de aquello religioso poco o nada instituido, interpelando no obstante a los contemporáneos. ¿No se tratará del dinamismo de la teología y de estar abiertos a la escucha de lo religioso actual, de esas manifestaciones espirituales plurales, extrañas, pero no obstante significativas para muchos de nuestros contemporáneos? Dialogar con el mundo contemporáneo es hacerse cargo del desplazamiento de este instinto dialogal en un contexto diferente, más cerca de nosotros y definido por el hoy. Esto no es una tarea cualquiera. Esta estimulante proximidad con lo contemporáneo permite colaborar teológicamente con la construcción de un mundo mejor. Sin embargo, esta proximidad también es arriesgada puesto que da cuenta de

2 Cette première partie reprend de manière succincte certains propos d'un article publié à la suite d'une communication faite dans un colloque à l'université de Montréal. Voir Marc Dumas, «L'expérience de la théologie: corrélation, interruption et recontextualisation», in Théologiques, 14/1-2, 2006, 117-126.

3 Voir à ce propos certaines propositions analysées dans Marc Dumas, «Les distinctions entre théologie, sciences religieuses et sciences des religions», in Studia canonica, 37/2, 2003, 467-481. 
M. Dumas. (2020). "La experiencia de la teología: explorar lo teologal en la profundidad de lo humano y de la sociedad" en Palabra y Razón. Revista de Teologia, Filosofía y Ciencias de la Religión. № 17 Julio 2020, pp 9-24 https://doi.org/10.29035/pyr.17.9

la distancia que emerge, y es donde el discernimiento no debe dejar de repensarla. Proponer una teología transgresiva, que abre un camino nuevo para nuestro hoy, exige este riesgo. ¿Cómo releer la teología en el mundo? ¿Cómo posicionarla de cara a las nuevas sensibilidades de la cultura? Los esfuerzos de recontextualización teológica son necesarios, si queremos ilustrar su pertinencia y disipar las preguntas incómodas que acabamos de formular. ¿Cómo abrir un camino que "una" las nuevas situaciones del hoy? Pero también: ¿Cómo descoincidir de lo que atraparía e impediría vivir lo teologal? Solo tres breves apuntes sobre las condiciones de la práctica teológica antes de explorar las estrategias de descoincidencia de los teólogos.

— La expresión "La experiencia de la teología", reenvía a algunos a la sabiduría adquirida a lo largo de milenios; a lo que esta sabiduría ha atravesado en el pasado. No obstante, esta expresión nos instala también en lo que esta experiencia enfrenta en nuestro espacio-tiempo. La experiencia de la teología puede ser ancestral, rica, imponente, posiblemente adquirida sobre fundamentos y ser dogmática. Esta experiencia puede ser, también, situada, frágil, arriesgada, limitada, abierta a colaborar con los proyectos de vida contemporáneos, en el momento que busca situarse en los horizontes del sentido, en las irrupciones religiosas o en las corrientes espirituales, en el reencuentro de las grandes religiones o, aún más, en la pluralidad y en la diversidad social. Recordemos que los contextos y las circunstancias han condicionado siempre las prácticas teológicas. Sin embargo, si estas responden al contexto se distinguen de él, en tanto testimonian prioritariamente lo teologal. Las prácticas teológicas son, entonces, siempre las testigos de descoincidencias, de las separaciones, de los excesos. La teología abre por consecuencia a una inteligencia diferente a la de las ciencias humanas. De esta manera, puede criticar de otra forma aquello que obstaculiza el anuncio del Evangelio; puede inscribirse como germen de la transformación social que contribuya a "un dar cuenta de la fe" pertinente para los seres humanos. Resumiendo, la teología está en contradicción con las expectativas y puede ofrecer una luz diferente. Se vuelve entonces necesario desplegar estrategias para inscribir el posible aporte de la teología y de la fe en las situaciones contemporáneas que son leídas de manera frecuentemente más superficial.

Si el trabajo teológico a través de las épocas es un diálogo entre el contexto y lo teologal, podemos comprender por qué este trabajo busca tanto explicitar racionalmente la fe de la comunidad creyente, la misma que da cuenta de esta fe en el mundo en el que viven los creyentes. La inteligencia de la fe utilizará herramientas disponibles en una época y dispondrá sin 
M. Dumas. (2020). "La experiencia de la teología: explorar lo teologal en la profundidad de lo humano y de la sociedad" en Palabra y Razón. Revista de Teologia, Filosofía y Ciencias de la Religión. № 17 Julio 2020, pp 9-24 https://doi.org/10.29035/pyr.17.9

cesar, a lo largo de los tiempos y de una manera extraordinaria, la materia experiencial de fe. Debería sumar a esta materia de fe el acto de la fe; es decir el hecho de que la fe responde a una presencia teologal en el centro del mundo. Y a pesar de las condiciones cambiantes de este diálogo, permanece una necesidad ineludible, una exigencia metodológica que no debe ser borrada entre la fe, la tradición y la teología, por una parte, y la cultura y la sociedad por otra.

— Una segunda observación pretende recordar cómo las teologías del Siglo XIX y XX se han desplegado a partir de un principio de continuidad entre la fe y la cultura. La recontextualización de la fe cristiana se adhiere a los diferentes procesos socioculturales modernos para inscribir los lugares de acción del Dios salvador. Los criterios epistemológicos modernos están integrados en las reflexiones teológicas, y las teologías de la correlación articulan la relación entre fe y cultura. Desarrollado de manera magistral por Paul Tillich, el método correlativo insiste sobre la continuidad, la armonía y una superposición importante de la fe y la cultura. Este método no pudo ser retomado y mejorado por diferentes teólogos de la segunda mitad del siglo XX puesto que, aunque era prometedor, este se encontraba cada vez con una mayor resistencia, no dando los frutos esperados.

La emergencia de una situación totalmente nueva, critica los parámetros de la modernidad, lo que engendra nuevas sensibilidades epistemológicas y conduce a la teología a una recontextualización. Estas sensibilidades nuevas se manifiestan a través del carácter polimorfo y plural de lo religioso y de la vida cristiana propiamente tal, pero también a través de las diferentes visiones del mundo y de los múltiples estilos de vida. Se vuelve más difícil afirmar en este contexto la existencia de un diálogo singular entre fe y cultura. El trabajo dialogal se vuelve más complejo ante la pluralidad de elementos asociados: hay fes, teologías, culturas, enre otros. La radicalidad de la heterogeneidad deja obsoleto el discurso hegemónico nivelando la diferencia del otro. Se releva la contingencia de construcciones de sentido, sus límites, sus caracteres situados y particulares. Estas sensibilidades a lo otro y a la diferencia, critican la tendencia totalizante de concluir fácilmente en el consenso y la armonización. En este contexto nuevo, la posición de puro observador no tiene más lugar; un espacio es dado a los participantes que están en relación, en confrontación, en conflicto. Desgastada en las conciencias, la fe religiosa cristiana de los contemporáneos se desvanece, la cultura cristiana está entonces desafiada por una cultura postcristiana y plural, que puede cuestionar la identidad específica de los creyentes. El entusiasmo por la pluralidad religiosa, las grandes religiones y los diferentes estilos de 
M. Dumas. (2020). "La experiencia de la teología: explorar lo teologal en la profundidad de lo humano y de la sociedad" en Palabra y Razón. Revista de Teología, Filosofia y Ciencias de la Religión. $\mathrm{N}^{\circ} 17$ Julio 2020, pp 9-24 https://doi.org/10.29035/pyr.17.9

vida, contribuye a este cuestionamiento de la identidad de los cristianos y cristianas.

— ¿Cómo recuperarse teológicamente en la posmodernidad? ¿Cuáles son las estrategias teológicas desplegadas en este contexto posmoderno? Identifico tres estrategias. Las dos primeras están en detrimento ya sea del diálogo con el contexto o del carácter propiamente teologal del trabajo teológico. La primera estrategia se esfuerza en re-teologizar el mundo, de realizar un mejor retrato de él, puesto que es comprendido como negativo y alienante. Su olvido de Dios conduce a un repliegue hacia una anterioridad original de la relación a Dios, anticipando los desarrollos del teísmo y del ateísmo moderno. En este punto, se privilegia la ruptura radical con el contexto, en el entendido que el don de Dios o su espacio están en otra parte.

La segunda estrategia inscrita en el horizonte moderno, permite a la teología ejercerse como proyecto correlativo entre la tradición y de fe y cultura moderna. En esta estrategia, se hacen ajustes dogmatizando al límite una continuidad irreductible entre lo humano y lo cristiano, entre la antropología y la teología. La insistencia unilateral sobre la continuidad entre el anthropos y el theos, oculta el sentido propio de la teología y funcionaliza de tal manera el carácter antropológico, que la dimensión teologal aparece como una repetición, el color cristiano es un símbolo, un rito es un relato. El esfuerzo de perseguir a cualquier precio la correlación, oculta la dimensión específica de la fe, la que se vuelve una suerte de marco de gestión terapéutica o, aún más, una función que apunta a favorecer el desarrollo y la coexistencia humanas. La dimensión teologal es olvidada. De tales trabajos teológicos no vemos todavía cómo lo teologal no coincide en su inscripción con el pliegue y el repliegue de la historia, de lo humano y de la sociedad. Estos trabajos no dan cuenta, aún, de cómo esta inscripción debilita y transforma las diferentes lecturas. La tercera estrategia teológica toma diferentes nombres según los autores. Nosotros podríamos hablar de ella como la estrategia de la descoincidencia. Este es el objeto de la segunda parte.

\section{Explorar lo teologal en la profundidad de lo humano y de la sociedad es operar en descoincidencia ${ }^{4}$}

Esto es lo esencial del propósito que a continuación se expone. Nos tomaremos más tiempo en explorar este sendero del ejercicio teológico,

4 Cette seconde partie reprend partiellement une communication faite dans un colloque à l'Acfas en 2016. Une version française a été soumise et acceptée pour une publication à venir: Étudier le religieux au Québec, dirigé par J.-P. Perreault, J.-F. Laniel et D. Koussens, Québec, PUL, 2020. 
M. Dumas. (2020). "La experiencia de la teología: explorar lo teologal en la profundidad de lo humano y de la sociedad" en Palabra y Razón. Revista de Teologia, Filosofía y Ciencias de la Religión. № 17 Julio 2020, pp 9-24 https://doi.org/10.29035/pyr.17.9

puesto que imaginamos que es posible articular mejor, en un contexto posmoderno, la manera en la cual sería posible tener una experiencia de la teología significante y pertinente. Los análisis interdisciplinarios de los fenómenos religiosos permiten, ciertamente, describir los lugares de lo religioso en la actualidad, los más tradicionales y también los más emergentes. De una sociedad relativamente homogénea donde los lugares estaban claramente definidos para expresar lo religioso (credo, textos sagrados, ritos, símbolos, comunidades de fe), nos enfrentamos en la actualidad a la experiencia de erosiones, de recomposiciones y de emergencias religiosas y espirituales nuevas. En este contexto de efervescencia, algunas estrategias teológicas parecen amenazadas por la desintegración, puesto que estas serían incapaces de cambiar el rumbo de cara a los nuevos desafíos contemporáneos. En esta segunda parte, quisiéramos poner en evidencia aquello en lo que los teólogos insisten para poner a lo teologal en el centro de los desplazamientos y las trasformaciones socio-religiosas. En esta línea, me parece que la práctica teológica debería, mínimamente, tomar en cuenta dos elementos: el contexto y lo teologal. La práctica teológica no puede, en efecto, separarse del contexto, incluso abstraerse de la vida concreta de hombres y mujeres; no puede hacer caso omiso de los nuevos espacios en los cuales lo humano construye su mundo. La práctica teológica debería también, y más específicamente, dar cuenta de las huellas, de la dinámica de presencia y ausencia de lo teologal en el centro de lo humano y del mundo. Sin embargo: ¿qué entendemos por la palabra teologal?

Lo teologal nos devuelve al soplo de la Ruah que planeaba sobre las aguas al principio de la creación en el Génesis, al fuego de la zarza ardiente que Moisés encuentra en el desierto o, más aún, a la transparencia de Dios a través del decir y los actos de Jesús de Nazaret. Lo teologal refiere a aquello que trasciende nuestra materialidad, a lo que nos supera y que se nos escapa, a lo divino; menos, quizás, al fundamento o a lo voladizo como en el pasado, sino más bien al corazón de lo humano y de su vida personal y colectiva, social y política.

Incluso si las proposiciones y reflexiones de Paul Tillich (18861965), de Miche de Certeau (1925-1986), de Pierre Gisel (1947-) o incluso de Lieven Boeve (1966-), han servido de catalizadoras para precisar el entramado de esta investigación teológica en tipo modernidad avanzada, me detendría principalmente sobre las dos primeras figuras, haciendo solo algunas alusiones a los trabajos de los dos últimos. Quisiera aquí subrayar el aporte de descoincidencia de la perspectiva teológica de cara a los fenómenos religiosos contemporáneos $\mathrm{y}$, por consecuencia, abogar 
M. Dumas. (2020). "La experiencia de la teología: explorar lo teologal en la profundidad de lo humano y de la sociedad" en Palabra y Razón. Revista de Teología, Filosofia y Ciencias de la Religión. $\mathrm{N}^{\circ} 17$ Julio 2020, pp 9-24 https://doi.org/10.29035/pyr.17.9

por un diálogo interdisciplinario más inclusivo del carácter teologal de lo religioso, del cual la investigación teológica es testigo.

\subsection{La incondicionalidad de Paul Tillich}

La religión es la experiencia de lo incondicional, es decir, la experiencia de la realidad absoluta sobre la base de la experiencia de la nada absoluta. Esta es la experiencia de la nada de lo que existe, de la nada de los valores, de la nada de la vida personal. Ahí dónde esta experiencia ha conducido a lo no absoluto, radical, se transforma repentinamente en una experiencia también absoluta de la realidad, en un sí radical. No se trata de una realidad nueva, al lado o por sobre las cosas: esto sería, entonces, solamente una cosa de orden superior que caería bajo el no. Sin embargo, a través de las cosas esta realidad se nos impone, la cual es al mismo tiempo el no y el sí a las cosas. Esto no es un ser, no es la substancia, no es la totalidad de lo que es. Es, para emplear una fórmula mística, el más allá del ser, el cual es al mismo tiempo la nada absoluta y lo algo absoluto. No obstante, el predicado "es" enmascara el hecho de que no se trata de una realidad de ser, sino más bien de una realidad de sentido y, además, del sentido último, el más profundo, que estremece todo y edifica todo de nuevo. ${ }^{5}$

Así se expresaba Paul Tillich hace 100 años en su conferencia sobre una teología de la cultura. Esta cita articula diferentes elementos que explicitaremos en lo que sigue. En principio, la investigación teológica, si es que está habitualmente asociada a una comunidad de fe, puede también encontrar otros lugares de anclaje contextuales para desplegarse a través de todas las funciones de la cultura, en el espacio social y en el corazón de la existencia humana. Así, podemos imaginar una práctica teológica que se interesa por lo incondicional, trabajando la creatividad de hombres y mujeres y manifestándose en el arte, la moral o la política, en la ciencia o en la salud, en resumen, en todas las funciones de la cultura. Posteriormente, la religión, si la asociamos habitualmente a una doctrina o a credos, a creencias o instituciones, se comprende entonces como una dinámica, como una irrupción del sentido último que se sacude y trastoca, atraviesa y transforma las formas de lo condicional. En otros textos de la teología de Tillich, nociones análogas vendrán, según los contextos, a articular esta irrupción de la radicalidad, esta sacudida y este vuelco de la realidad. Yo comparo a veces esta irrupción con un punto sobre una línea o, aún más, con un punto sobre una superficie; este punto es el sorprendente e inesperado avance de lo Eterno en lo temporal. Este punto es lo inaudito del silencio que se escucha en el eco de nuestras conversaciones; este

5 Paul Tillich, «Sur l'idée d'une théologie de la culture», in Paul Tillich. La dimension religieuse de la culture. Ecrits du premier enseignement (1919-1926), Jean Richard et coll. Éd., Québec/Paris/ Genève, PUL/Cerf/Labor et Fides, 1990, 35-36.) 
M. Dumas. (2020). "La experiencia de la teología: explorar lo teologal en la profundidad de lo humano y de la sociedad" en Palabra y Razón. Revista de Teología, Filosofía y Ciencias de la Religión. $\mathrm{N}^{\circ} 17$ Julio 2020, pp 9-24 https://doi.org/10.29035/pyr.17.9

punto es constitutivo de la línea o del plano; él les permite... finalmente, la realidad incondicional del cual estamos hablando. Si es que esta es habitual o espontáneamente asociada a Dios se distingue, también, de él, puesto que ya en el contexto de los años 20 la palabra Dios era difícil de utilizar. ${ }^{6}$

No obstante, la palabra Dios se ha vuelto inutilizable, sobre todo porque es la cuestión que trasciende todas nuestras representaciones. En relación a lo anterior Tillich hablará al final de su vida como "de Dios más allá de Dios", God above God. Los años 20 servirán para testear y desarrollar este proyecto de teología abierta a las creaciones culturales que las considera como médiums de lo incondicional. Tillich cree percibir lo incondicional en las manifestaciones de lo condicional; él desarrolla herramientas críticas para evitar la reducción de lo incondicional a lo condicional (proceso de profanación), o también para evitar hacer de lo incondicional un elemento de los condicional (proceso de absolutización). Mejor todavía, la noción de demoniaco viene a criticar una irrupción torcida de lo divino que conduce a una realización creadora y destructora, tanto a nivel personal como social.

Entonces el proyecto de Tillich de una teología de la cultura, busca evitar la desintegración de la teología en la sociedad; insistiendo sobre el carácter irruptivo de lo divino en todas las funciones de la cultura, Tillich hace ver que el ejercicio teológico no está únicamente reservado al "pequeño resto" de la comunidad de la fe. Hacer teología es para todos y supera las fronteras confesionales. Tillich desarrolla una reflexión teológica respetando la autonomía moderna y la irrupción de lo sagrado en lo profano. Hoy en día, el horizonte de pensamiento se ha transformado profundamente. Las críticas dirigidas al ejercicio teológico por otras corrientes científicas de lo religioso, aún lo ponen en cuestión. Y es importante clarificar el porqué, en qué y por qué la investigación teológica contemporánea hace sentido. ¿Tiene pertenencia en un mundo cada vez más secularizado? ¿Cómo se distingue de otras ciencias que se interesan por lo religioso?

Para responder a estas cuestiones, es preciso superar la postura tillichiana y concebir la tarea de la teología como a la caza de lo teologal, incluso ahí donde no se la espera. Y es precisamente porque su "objeto" escapa a otras ciencias, que la teología puede tener pertinencia no solamente para los creyentes, sino para todos; su "objeto" resiste a la asimilación y a la reducción, a la integración y a la totalización. El ejercicio teológico tiene

6 Voir Paul Tillich, «Discussion de Tillich avec Barth et Gogarten. Réponse de Tillich à Barth (1923)», in Paul Tillich. Écrits théologiques allemands (1919-1926), Marc Dumas, Éd., Québec/ Genève, PUL/Labor et Fides, 2012, 105. 
M. Dumas. (2020). "La experiencia de la teología: explorar lo teologal en la profundidad de lo humano y de la sociedad" en Palabra y Razón. Revista de Teologia, Filosofía y Ciencias de la Religión. № 17 Julio 2020, pp 9-24 https://doi.org/10.29035/pyr.17.9

en vista aquello que se escapa (una alteridad borrada), o lo que atraviesa y transforma lo socio-cultural (prácticas de encarnación y de inscripción en el centro del mundo). Para profundizar esta intuición, exploramos algunos textos de Michel de Certeau y de manera algo menos profunda los Pierre Gisel y de Lieven Boeve.

De Certeau ha reflexionado teológicamente en las fronteras de las disciplinas, buscando no perder aquello que evocan los discursos teológicos, entendiendo que esto no es el objeto de las preocupaciones de muchos de sus contemporáneos. Gisel desplaza resueltamente la reflexión teológica del horizonte de la comunidad de fe al de la escena religiosa social; escena que nos interesa a todos puesto que está aún ahí para subrayar la tarea original del ejercicio teológico. Existe la preocupación por pensar el desfase y el exceso en relación a la escena social, la cual ha escondido durante demasiado tiempo, y guardado en silencio, sus gestos de diferenciación, de ruptura y de separaciones. Finalmente, Boeve propone comprender el diálogo entre el contexto y la fe en términos de interrupción, expresión análoga a la de descoincidencia priorizada en este artículo.

\subsection{La experiencia teologal en Michel de Certeau}

La escritura de de Certeau es una tensión entre la presencia y la ausencia; su escritura es impulsada por el deseo de lo ausente, de aquel o de lo que ha desaparecido. Nuestra corta detención en de Certeau nos permitirá comprender la importancia de los desafíos de la investigación actual. De Certeau reformula a través de sus diferentes trabajos sobre el pasado y el presente, a través de sus diferentes implicaciones en distintas redes intelectuales y a través de sus compromisos con lo urbano, cómo la experiencia teologal se dice, se expresa y se sustrae, teniendo en cuenta las transformaciones fundamentales que han ocurrido en la Modernidad. La luz que arroja respecto de la dinámica presencia-ausencia de Dios, conduce a un discurso teológico diferente, que asume una presencia teologal en ruptura con lo religioso tan domesticado, y en tránsito hacia otras realidades mundanas. La postura teológica como experiencia en de Certeau: ¿no permite proponer un decir teologal con sentido para nuestros contemporáneos y distinto (u original) respecto de otros discursos sobre lo religioso?

Este universo despliega un trabajo del pensamiento que atraviesa diferentes epistemologías contemporáneas: de la historiografía, de la antropología, del psicoanálisis, de la espiritualidad o de la mística. Este universo en constante desplazamiento abre a la diferencia; marca las fallas y 
M. Dumas. (2020). "La experiencia de la teología: explorar lo teologal en la profundidad de lo humano y de la sociedad" en Palabra y Razón. Revista de Teologia, Filosofía y Ciencias de la Religión. № 17 Julio 2020, pp 9-24 https://doi.org/10.29035/pyr.17.9

las divergencias y se resiste a la comprensión y a la sistematización habitual; todo esto permite pensar lo impensable, demasiado frecuentemente dejado de lado por las ciencias sociales y humanas.

Incluso si la experiencia religiosa, la que es cuestionada, en la obra de de Certeau lleva muchos nombres según sean las épocas, podría resumirse de la siguiente manera: en primer lugar el momento de la voix (voz) con una " $\mathrm{x}$ ", porque una palabra (de Dios), caracterizada por una eficacia, engendra la creación, la vida, el amor y la transformación del mundo. En resumen, llama o interpela a lo humano a una respuesta, a una responsabilidad, a una acción. Después viene el momento de la voie (vía) con una "e", porque la Palabra abre una vía, un camino, inicia un itinerario, una errancia. Finalmente, ocurre el momento de un lugar cotidiano de encuentro del Otro a través de los otros, un lugar de deseo y de tránsito, un lugar comunitario cuya única estabilidad está en enviar al caminante más lejos. Estos tres momentos articulan una dinámica de presencia-ausencia de Dios que marca la experiencia (mística) en de Certeau; ésta es la que se inscribe en el corazón de los deseos de sentido y de transformación del mundo. Dios pone a lo humano en marcha, lo invita a dejar, como Abraham, un mundo conocido por otro que está en otra parte. Dios mueve el infinito, y de una manera loca, hacia el Otro y los otros. Dios inicia una acción teologal inesperada, sorprendente. Dios descoincide.

Si el tema de la experiencia se repite regularmente en la escritura de de Certeau, los diferentes epítetos que desarrolla a lo largo de sus publicaciones ¿no anuncian a su manera un camino teologal?

De lo religioso a la fábula... ¡mística! No es posible proponer una simple correspondencia entre las experiencias contemporáneas y un lenguaje de fe que sería el de antes de la modernidad. La correlación de experiencias fragilizada por la brecha difícilmente franqueable entre el mundo y la fe, se vuelve cada vez más una no-correlación. De Certeau subraya cómo la experiencia es una no-experiencia, una experiencia de aquello que escapa y que, sin embargo, busca decirse en las existencias y en aquello que ocurre en el mundo.

Veamos otra puesta en escena de nuestro autor respecto de la experiencia teologal a través de una nueva descripción de los momentos de la experiencia, tal como lo formula en el texto "La experiencia espiritual". 7 Esta formalización, útil pero engañosa, corre el riesgo de localizar aquello que es del orden del deseo y de la espera, del orden de lo indefinido y

7 Voir Michel De Certeau, «L'expérience spirituelle», in Christus, Vol. 17, no 68, 1970, 488-498. 
M. Dumas. (2020). "La experiencia de la teología: explorar lo teologal en la profundidad de lo humano y de la sociedad" en Palabra y Razón. Revista de Teologia, Filosofía y Ciencias de la Religión. № 17 Julio 2020, pp 9-24 https://doi.org/10.29035/pyr.17.9

de lo absoluto, de lo desvinculado. La primera etapa es la de un lugar, la del acontecimiento. Lo que ocurre no se comprende más que después. En este o en esos momentos particulares e imponentes, una irrupción abre una brecha, un agujero se produce. Estos momentos de ruptura, de explosión o quebradura de los límites, permiten decir que ¡Dios está ahí! La segunda etapa es del orden del itinerario o de la historia. El agujero o lo que de alguna manera ha irrumpido se vuelve el punto de partida de un camino, de una búsqueda, de un deseo que no deja de descubrir que es engañado por cada una de sus expresiones. El instante particular llama a un itinerario indefinido, siempre insatisfactorio. Un momento inicial, donde yo reconozco que él está ahí, hace posible un segundo momento, el de un andar indefinido, que da cuenta de que él no está ahí, que él viene y que yo no puedo atraparlo aquí o allá. "El caminar" no termina; lo que conocemos o percibimos de esto está descartado para dar un paso más. El llamado permanece indefinido; este gesto indica la distancia que modula el acto de conocimiento en la fe. La tercera etapa indica cómo lo infinito aparece: es aquí, en la presencia del otro en la profundidad de lo cotidiano que el infinito se insinúa sin que lo sepamos. "Lo infinito se insinúa en nosotros por la tensión interna y por el trabajo que se nos encomienda, a la vez, en las fisuras de nuestro tiempo y en la lentitud de nuestros pasos, en la sorpresa de momentos privilegiados y en los itinerarios silenciosos de una aparente repetición"8. Lo otro del otro o de los otros, lo otro del lenguaje o lo otro del tiempo, aparecen como lugares de manifestación de Dios, sin que este último se deje poseer. El texto de 1956 sobre la experiencia religiosa nombraba ya estos lugares de manifestación, teniendo cuidado de subrayar que la estructura de la experiencia lleva la fisura de la alteridad en el tiempo, el lenguaje y los otros, lo que permite desplegar una actividad paradojal, es decir una pasividad frente a la venida de Dios, frente a su paso. ${ }^{9}$

En el tomo primero de la Fable mystique ${ }^{10}$ (Fábula mísitica), de Certeau rescata textos maduros y trabajados por epistemologías cruzadas. El autor maneja a estas últimas de una manera notable, de tal forma que puede formalizar el cómo la experiencia, en un tiempo de turbulencia y de crispación institucional, migra hacia lo se llama la mística, y cómo esta se instala escindida respecto de lo instituido. Este modo místico, que produce giros lingüísticos particulares de las santas y los santos: ¿no podría ser estimulante para, aún más, trabajar teológicamente en la actualidad? Encontramos aquí, en efecto y bajo este modo, un ejercicio teológico

8 Ibid., 495.

9 Voir Michel De Certeau, «L'expérience religieuse, 'connaissance vécue' dans l'Église», Recherches de science religieuse, vol. 76, no 2, 1988, [1956], 187-211.

10 Voir Michel De Certeau, La Fable mystique, Tome 1, Gallimard, 1982. 
M. Dumas. (2020). "La experiencia de la teología: explorar lo teologal en la profundidad de lo humano y de la sociedad" en Palabra y Razón. Revista de Teologia, Filosofía y Ciencias de la Religión. $\mathrm{N}^{\circ} 17$ Julio 2020, pp 9-24 https://doi.org/10.29035/pyr.17.9

liberado de etiquetas doctrinales reificadas, que explora el trabajo de lo teologal en lo profundidad de lo humano y de su sociedad.

De Certeau cartografía aquello que se nos escapa, lo que excede, lo que separa del lugarteniente, de lo apropiado institucionalmente. Su escritura da cuenta de la pérdida y de la ausencia, por una parte; por otra, ella ilustra cómo el deseo de reencuentro se vuelve el motor que mueve a los santos y los desplaza: ellos escriben, fundan instalaciones, no-lugares de fe para vivir, de esperanza y de caridad; ellos se pierden, se separan para dejar surgir desde el interior del espíritu, que da paz, precisamente porque ellos caminan más lejos. Nuestra reflexión sobre lo teologal exige dejar nuestros propios universos normados e invita a tomar senderos desconocidos. Esta reflexión sigue la huella dejada por lo teologal con todo el rigor y seriedad posible, incluso si esta tiene como objeto aquello que se le escapa y que es no-normalizable; esto invita a otra práctica teológica; rastreando lo teologal en los pliegues y repliegues de la experiencia, esta práctica sirve para realzar la experiencia humana y social, mostrándole la fisura, lo prohibido, el exceso...

Tenemos aquí un gesto teológico transgresor, puesto que la experiencia se abre a las huellas de lo teologal gracias al trabajo teológico. De Certeau, refiriéndose a la experiencia religiosa, investiga el texto para desprender a través de lo dicho, lo que la transgrede, lo que la supera y reenvía al otro/Otro. Da cuenta de lo que resiste a una hermenéutica teológica orgánica, la que se contentaría con validar sus correlaciones con el horizonte de la tradición cristiana. Él se sumerge, por el contrario, en la textura contemporánea para actualizar lo inaudito de lo teologal.

\subsection{La escena religiosa giseliana y la interrupción boeviana}

Muy breve e injustamente por falta de espacio, evoquemos los trabajos de Gisel y de Boeve.

Gisel reflexiona rigurosamente sobre los desplazamientos y en la apertura necesaria que la teología debe realizar para que su especificidad no se pierda en el mundo actual. Consciente de las tensiones pasadas y presentes entre la teología y las ciencias religiosas, desarrolló en el transcurso de las dos últimas décadas, una posición estimulante, que guarda relación con el carácter específico de lo teologal en el centro de lo humano y del mundo. Desde 199911, Gisel está ya consciente del espacio cada vez

11 Voir Pierre Gisel, La théologie face aux sciences religieuses. Différences et interactions, Labor et Fides, 1999. 
M. Dumas. (2020). "La experiencia de la teología: explorar lo teologal en la profundidad de lo humano y de la sociedad" en Palabra y Razón. Revista de Teología, Filosofia y Ciencias de la Religión. $\mathrm{N}^{\circ} 17$ Julio 2020, pp 9-24 https://doi.org/10.29035/pyr.17.9

más diversificado ocupado por lo religioso y la religión en la sociedad moderna, y pretende poner en juego a la teología en este nuevo contexto, clarificando la originalidad, la necesidad y la interacción complementaria con las ciencias religiosas. ¿No puede acaso la teología permitir otra visión de lo religioso, de ver otra cosa en el centro de lo humano y del mundo que lo que las ciencias religiosas describen? Estas últimas se ocupan de lo religioso o de lo que atraviesa humanamente lo religioso (ritos, símbolos, textos, entre otros.); la teología trata sobre lo absoluto, de la fe o del creer, en resumen, de lo que la atraviesa, pero sin jamás ser asimilable o reductible a una inscripción en la historia, en lo social o en lo religioso institucionalizado.

Para esto, el ejercicio teológico debe operar importantes desplazamientos; el horizonte teológico no está únicamente reservado a la Iglesia, sino que está abierto al mundo de todos, la teología debe abrirse radicalmente a las realidades antropológicas y sociales, y debe poder dar cuenta al interior de una racionalidad pública de su trabajo que implica a Dios o al absoluto. La teología puede tratar el pluralismo religioso en las sociedades y evidenciar cómo el absoluto está siempre en acción en las concreciones antropológicas y sociales, así como las diversas simbolizaciones que se han desarrollado a través de la historia.

En la obra de Gisel, las herencias de la fe cristiana y los instintos teológicos no se quedan atrás ${ }^{12}$. Por el contrario, a través de estos diferentes lugares de regulación, las prácticas teológicas han trabajado el hecho cristiano como inscrito en la historia y en el corazón de las naciones. ¿no sería sino a través de la existencia humana (como los dispositivos socioculturales) que se anuncia aquello que desborda y abre a lo teologal? Si la referencia al Dios cristiano no es más evidente en nuestras sociedades, seguimos teniendo otros tipos de discursos sobre Dios o sobre la religión y lo religioso. El instinto teológico que se ocuparía finalmente de superar la cristalización efectiva del hecho cristiano: ¿no puede ser retomado en nuestros nuevos contextos? Lo religioso está ligado al absoluto y al exceso, y este lazo está al origen de un desfase con el mundo mismo, el cuerpo, lo social, lo institucional y la historia: desfase que es necesario reflexionar, todavía, teológicamente en la actualidad.

Lo que interesa teológicamente no es la simple y llana evolución, sino a la inversa: las rupturas y las fracturas en la historia que pueden dar testimonio de lo absoluto.

12 Voir Pierre Gisel, «La théologie face à ses héritages», dans Marc Boss \& Raphaël Picon (dir.), Penser le Dieu vivant. Mélanges offerts à André Gounelle, Paris, Van Dieren, 2003, p. 337-357 et 494-496. 
Según Gisel, hay lugar para "una inteligencia de lo humano y de lo divino más allá de lo que las ciencias humanas y la historia de las religiones muestran"; "hay lugar para una disciplina que recupere el gesto de descentramiento y de interrogación que indicaba Platón, y al cual llamaba teología"13. La teología puede desarrollar un gesto que tenga por objetivo una visión de lo humano y de lo divino. Esta es una manera de trabajar y de interrogarse. Para el autor, la teología debe tener como interés primero las temáticas del creer y de la trascendencia sin caer en los defectos de la exculturación teológica, de la reducción ideológica y también del repliegue identitario. El interés se despliega ciertamente sobre las mediaciones y las transacciones antropo-socio-históricas, pero en tanto ellas son portadoras de exceso y llevadas por el exceso. A pesar de los esfuerzos por negar el exceso en nuestras sociedades, siempre hay quienes se oponen y dan vuelta testimoniando lo contrario.

Gisel compromete entonces cada vez más a la teología en desplazamientos para hacerla trabajar sobre la escena socio-cultural, para invitarla a salir de sí misma y a recuperar lo que la distingue de otras ciencias. Lo religioso no puede ser separado de lo social y de lo cultural; él es su resorte, no lo religioso normado, descrito y recuperado, sino más bien lo religioso profético, transgresivo, irruptivo, que ata al corazón de los cuerpos/corpus el deseo loco del otro, de lo que hace vivir ${ }^{14}$.

Boeve ha publicado bastante sobre el tema de la irrupción desde los inicios del $2000^{15}$. De cara a la falla de los métodos correlativos modernos: ¿Cómo inscribir el gesto dialogal de la teología con el mundo, la cultura y la sociedad en el nuevo contexto? ¿Cómo superar el cuestionamiento de la identidad específica de la fe cristiana y dialogar con una cultura cuyos contornos son plurales, situados, complejos, sin caer en un relativismo cultural, pero aún, sin olvidar la dimensión teologal específica de la fe cristiana? Boeve responde a estas preguntas presentando su tesis con la ayuda de una doble perspectiva: las perspectivas ad extra y ad intra. Se podría hablar de movimientos o de instintos suscitados por el diálogo

13 Pierre Gisel, «La théologie comme intelligibilité du croire», dans François Coppens (dir.), Variations sur Dieu. Langages, silences, pratiques, Facultés univ. Saint-Louis, 2005, 103-118, ici 115 .

14 Voir aussi Pierre Gisel, «Place, fonction et forme de la théologie» Recherches de science religieuse, vol. 96, no 4, 2008, 503-526; Pierre Gisel, «Théologie et sciences religieuses à l'enseigne de la sécularisation. D'une dualité à déplacer», Recherches de science religieuse, vol. 101, no 2 , 2013, 181-199; Pierre Gisel, «Mutations du théologico-politique. Quels déplacements, quels défis, quelles tâches?», Archives de sciences sociales des religions, no 169, 2015, 63-83.

15 Voir par exemple Lieven Boeve, Interrupting Tradition. An essay on Christian Faith in a Postmodern Context, Louvain, 2003; Lieven Boeve, «La definition la plus courte de la religion: interruption», in Vie consacrée, 75, 10-36. 
M. Dumas. (2020). "La experiencia de la teología: explorar lo teologal en la profundidad de lo humano y de la sociedad" en Palabra y Razón. Revista de Teologia, Filosofía y Ciencias de la Religión. № 17 Julio 2020, pp 9-24 https://doi.org/10.29035/pyr.17.9

entre la fe y el contexto. La interrupción aparece aquí como la clave del reencuentro y del diálogo. ¿La interrupción de una alteridad irreductible no podría ser un lugar teológico, un lugar donde percibir las huellas de Dios? ¿No sería proyectable considerar al Otro interrumpiendo nuestros relatos a través del encuentro y la confrontación con los otros? Una hermenéutica interrumpida permanece infinita y abierta; esta no se crispa, no se estanca ni desliza hacia una actitud fundamentalista. El encuentro interruptivo de la alteridad irreductible evita absolutizar la particularidad, una absolutización que arriesgaría un robo a la contextualidad o, más aún, un rechazo a una nueva experiencia de ser cristiano. Este encuentro interruptivo evita también la reducción del discurso cristiano a nivel de las estructuras humanas generales. La diferencia se encuentra en la similaridad. La pertinencia del relato cristiano es proporcional a su identidad, a su aptitud para recontextualizarse en un contexto marcado por la pluralidad. Esta evita finalmente toda confusión y recuperación de experiencias religiosas ambiguas sin perspectiva crítica.

Las perspectivas de Boeve participan del esfuerzo por recontextualizar el Evangelio. Confrontadas a la alteridad de otro, a la pluralidad y a la crítica postmoderna de los grandes relatos que instrumentalizan, las sensibilidades nuevas trabajan este esfuerzo de recontextualización. La pluralidad radical desarrolla una sensibilidad por la particularidad irreductible del relato cristiano. La alteridad del otro con el cual yo dialogo y que me interrumpe, me obliga a modificar la relación de la tradición al contexto. Las perspectivas metodológicas y estratégicas en este nuevo contexto pasan entonces por dos elementos para la teología: el diálogo y la interrupción. El diálogo se hace primero distinguiendo un movimiento ad extra y un ad intra, con el fin de clarificar cómo el encuentro con el mundo conduce a redescubrir, en el corazón de lo plural, la particularidad irreductible de la fe y cómo el examen de este nuevo contexto tiene consecuencias para el desarrollo de su propia narrativa; este examen confrontacional actúa como motor de recontextualización teológica. En segundo lugar, no olvidemos que algo interrumpe el relato, tanto el mío como el de los otros. La alteridad revela los límites de la posición.

\section{Conclusión: inquietarse por lo teologal aquí y ahora ahí donde no se le espera}

La hipótesis que ha sido sometida aquí, es que la investigación teológica puede instalarse en el seno de las dinámicas que rodean lo religioso, en lo humano y en el mundo, en la medida que se compromete, en el centro del mundo mismo, a reflexionar e interrogar las irrupciones, las 
rupturas, los desfases y las interrupciones engendradas por lo absoluto, ipor las descoincidencias! El ejercicio teológico puede inscribirse en el horizonte de lo social y de lo cultural; este ejercicio practica en este nuevo contexto lo que articulaba el sentido en el horizonte religioso de antaño. Para hacer esto, el ejercicio teológico es invitado a ponerse en marcha descubriendo lo teologal, y a dejarse sorprender por el absoluto en la profundidad de las aventuras y de los destinos de los contemporáneos. Continuar con el trabajo teológico es mantener unidos el contexto en el cual nos encontramos y el carácter propiamente teológico de nuestras actividades, lo que implica inquietarse por lo teologal. ¿Descoincidir no es acaso, en este punto, vivir en una ruptura instauradora, en desfase o en interrupción? Aparece entonces un nuevo relato abierto por Dios y las huellas de un Dios interruptor de relatos, de contextos y de Iglesias demasiado frecuentemente en modo de control, de retiro, de exclusión. Emerge un fino equilibrio (propio del camino que articula este des-camino) entre la continuidad y la discontinuidad que nos mantiene en modo de apertura, en modo de experiencia. También en su epistemología propia, así como otros, tales como los autores espirituales y místicos, aquellos de los escritos mistagógicos, de las páginas de los Testamentos, que se preocuparon por lo teologal, o de aquello que descoincidía de su contexto particular. Somos responsables frente a ellos aquí y ahora. 
